\title{
OFICINAS TERAPÊUTICAS COMO INSTRUMENTO DE REABILITAÇÃO PSICOSSOCIAL: PERCEPÇÃO DE FAMILIARES
}

\author{
Therapeutic workshops as means of psychosocial rehabilitation: perception of family \\ Talleres terapéuticos como herramienta para la rehabilitación psicosocial: percepción \\ de la familia
}

Dulcian Medeiros de Azevedo ${ }^{1}$

Francisco Arnoldo Nunes de Miranda²

\section{RESUMO}

As oficinas terapêuticas permitem a possibilidade de projeção de conflitos internos/externos por meio de atividades artísticas, com a valorização do potencial criativo, imaginativo e expressivo do usuário. Objetivou-se identificar a percepção dos familiares sobre as oficinas terapêuticas desenvolvidas. Pesquisa descritiva, com delineamento qualitativo, desenvolvida nos Centros de Atenção Psicossocial (CAPS) de Natal-RN, entre agosto e setembro de 2007. Foram entrevistados 28 familiares que participavam regularmente dos serviços. Os familiares destacaram o impacto positivo dos CAPS em suas trajetórias de tratamento e de vida, na melhoria da harmonia familiar. Sobre as oficinas terapêuticas, identificaram falhas e contradições, denunciando e apontando caminhos de superação. Percebem os espaços de participação nos CAPS como formas importantes de acompanhamento do seu familiar usuário, além do crescimento mútuo. As oficinas terapêuticas representam um instrumento importante de ressocialização e inserção individual em grupos, na medida em que propõem o trabalho, o agir e o pensar coletivos, conferidos por uma lógica inerente ao paradigma psicossocial.

Palavras-chave: Terapia pela Arte. Serviços de Saúde Mental. Família. Enfermagem Psiquiátrica. Transtornos Relacionados ao Uso de Substâncias.

\begin{abstract}
The therapeutic workshops allow the possibility of projection of internal / external conflicts through artistic activities, highlighting the creative, imaginative and expressive potential of the user. We aimed to identify the families' perception of the therapeutic workshops undertaken. The research descriptive, with qualitative design, developed in the Psychosocial Care Centers (CAPS) from $\mathrm{Natal} / \mathrm{RN}$ between August and September 2007. We interviewed 28 families who regularly attended services. Family members emphasized the positive impact of CAPS in the course of their treatment and life, in improving family harmony. On the therapeutic workshops, were identified failures and contradictions, exposing and pointing ways to overcome them. They realize the opportunities for participation in CAPS as important ways of monitoring their family user, in addition to mutual growth. The therapeutic workshops represent an important instrument of socialization and integration in individual groups, while it proposes working, acting and collective thinking, conferred by an inherent logic of the psychosocial paradigm.
\end{abstract}

Keywords: Art Therapy. Mental Health Services. Family. Psychiatric Nursing. Substance-Related Disorders.

\section{Resumen}

Los talleres terapéuticos permiten la posibilidad de la proyección de los conflictos internos / externos a través de actividades artísticas, con la valorización del potencial creativo, imaginativo y expresivo del usuario. El objetivo fue identificar la percepción de las familias acerca de los talleres terapéuticos realizados. Investigación descriptiva, con delineación cualitativa, desarrollada en los Centros de Atención Psicosocial (CAPS) en Natal-RN, Brasil, entre agosto y septiembre de 2007. Entrevistamos a 28 familiares que asistieron regularmente a los servicios. Los miembros de la familia destacaron el efecto positivo de CAPS en sus trayectos de terapéutica y de vida, en mejorar la armonía familiar. En los talleres terapéuticos, detectaron las deficiencias y las contradicciones, revelando y apuntando maneras para superarlos. Ellos perciben los espacios para la participación en CAPS como instrumentos esenciales para la observación de su usuario familiar, además de un crecimiento mutuo. Los talleres terapéuticos representan un importante instrumento de socialización e integración individual en grupos, al paso que se propone trabajar, pensar y actuar colectivamente, conferido por la lógica inherente al paradigma psicosocial.

Palabras claves: Terapia con Arte. Servicios de Salud Mental. Familia. Enfermería Psiquiátrica. Trastornos Relacionados con Substancias.

'Enfermeiro. Mestre em Enfermagem (PGENF-UFRN). Professor Assistente II do Curso de Graduação em Enfermagem (UERN), Campus do Seridó, Caicó-RN, Brasil. Líder do Grupo de Pesquisa "A enfermagem no processo saúde-doença individual/coletiva, na educação em saúde e na assistência/gerência de serviços de saúde". E-mail: professordulcian@gmail.com ,'Enfermeiro. Doutor em Enfermagem Psiquiátrica (EERP/USP). Professor Adjunto III do Departamento de Enfermagem (Graduação e Pós Graduação - UFRN), Campus Central, Natal-RN, Brasil. Líder do Grupo de Pesquisa "Ações promocionais e de atenção a grupos humanos em Saúde Mental e Saúde Coletiva". E-mail: farnoldo@gmail.com 


\section{INTRODUÇÃO}

A partir da Reforma Psiquiátrica em andamento, a assistência aos portadores de sofrimento psíquico vem passando por fortes mudanças, deslocando-se a centralidade dada à loucura para um sujeito real, de direitos, aspirações e anseios, integrante de uma família e inserido em uma certa comunidade. ${ }^{1}$

Mais que uma tentativa de demolir as paredes do manicômio e as práticas profissionais em saúde mental/ psiquiatria até então instituídas, com foco único na loucura, a Reforma apregoa a organização dos novos serviços de saúde mental, articulados por referência e contrarreferência, e em rede, conforme os princípios e diretrizes do Sistema Único de Saúde (SUS), defendidos a partir da $8^{\text {a }}$ Conferência Nacional de Saúde e presentes na Carta Magna. ${ }^{2}$

Nominados de substitutivos, estes novos serviços de saúde mental propõem ações e atividades na perspectiva e dimensão comunitárias, com a finalidade de reintegrar à teia social o "louco" e sua família, através de uma equipe multidisciplinar (equipe técnica). Assim, a partir da Reforma Psiquiátrica, os serviços substitutivos e os profissionais de saúde passam a enfocar não mais o atendimento individual do doente, destacando o transtorno mental como ponto central, mas a coletividade de seus relacionamentos afetivos, sociais, familiares e comunitários.

Nesse sentido, a família representa o espaço coletivo indispensável para a garantia da sobrevivência, desenvolvimento e proteção de seus membros, independente de seu arranjo ou da forma como se estrutura, possuindo uma dinâmica de vida específica. ${ }^{3}$ Logo, entende-se que não basta tratar o portador de sofrimento psíquico isoladamente, mas ofertar cuidados a todos aqueles que compõem o núcleo familiar. ${ }^{4}$

0 sofrimento psíquico de um membro familiar tende a circular entre todos os outros membros, e a precariedade da situação de vida de grande parte das pessoas contribui para o adoecimento, especialmente sua condição social. 0 enfoque voltado ao grupo familiar e ao contexto social possui resultados bem mais positivos e resolutivos do que aquele que reduz 0 membro à sua doença. ${ }^{5}$

A valorização e reconhecimento da família como unidade de cuidados, a partir de sua inserção na agenda terapêutica dos serviços de saúde mental, enquanto um agente ativo de participação ou transformação, além da propositura de desconstrução de um modelo de intervenção arraigado no imaginário social, representam um desafio para os profissionais de saúde. Tal fato exige uma mudança imprescindível nas práticas terapêuticas, configurando-se em um processo transicional entre a tradição da cultura manicomial e a nova proposta substitutiva/reformista.

Nesse sentido, o Centro de Atenção Psicossocial (CAPS) responde pela porta de entrada e regulação em saúde mental no SUS, sendo criado na intenção de substituir as internações nos manicômios pelo atendimento aberto na comunidade. Ele deve fornecer atendimento à população, com acompanhamento clínico e reinserção social dos usuários pelo acesso ao trabalho, lazer, exercício dos direitos civis, fortalecimento dos laços familiares e comunitários, além de oferecer suporte à saúde mental na rede básica. ${ }^{6}$

Atualmente, um dos grandes desafios do CAPS representa exatamente esta articulação intersetorial e social, capaz de (re)inserir o sujeito portador de sofrimento psíquico e sua família à dinâmica comunitária, através de ações e espaços melhor ampliados e estruturados em outros territórios. ${ }^{5}$

Nos últimos sete anos a expansão, a consolidação e a qualificação da rede de atenção à saúde mental, tendo no CAPS o centro estratégico, foram os objetivos principais das ações e normatizações do Ministério da Saúde. A partir do ano de 2003, apenas CAPS públicos foram cadastrados junto ao Ministério. Da mesma forma, os municípios receberam incentivos para a municipalização dos poucos serviços privados ou filantrópicos existentes há mais tempo na rede. Atualmente, quase $99 \%$ dos CAPS da rede são públicos.?

A proposta terapêutica do CAPS compreende uma série de atividades e dinâmicas diversificadas, que devem ser pensadas e discutidas por todos os atores que compreendem 0 serviço (gestor, profissionais da equipe técnica e demais profissionais de nível médio, usuários, familiares e comunidade adstrita).

Eleger a reabilitação psicossocial como mote/paradigma deflagrador desta nova forma de cuidados em saúde mental é defender atividades e ações que privilegiem as aspirações, anseios e preferências de usuários e familiares, respeitando-se suas subjetividades, além da valorização da coparticipação e da corresponsabilidade.

Dessa forma, destaca-se o acolhimento dos usuários e o projeto terapêutico individual, construído e idealizado conforme as necessidades de saúde/doença e realidade social encontrada, além do atendimento individual e de grupo. Como atividades coletivas destaca-se: as oficinas terapêuticas, os encontros e os passeios externos ao CAPS, as festividades em datas comemorativas, as assembleias e as reuniões, as atividades artísticas (expressão corporal, gestual, musical).

Nos CAPS, a arte em suas várias expressões vem sendo utilizada nas oficinas terapêuticas, embora em alguns casos a apropriação do seu campo conceitual pelos técnicos em saúde mental ainda ocorra de forma incipiente. A arte é capaz de produzir subjetividades, catalisar afetos, engendrar territórios desconhecidos e/ou inexplorados. Ainda que haja indefinição por parte dos profissionais da área quanto às formas de compreensão da relação entre arte e terapia, o seu valor na reabilitação está na possibilidade do usuário trabalhar e descobrir suas potencialidades para conquistar espaços sociais. ${ }^{8}$ 
0 desenvolvimento de oficinas terapêuticas nos CAPS permite a possibilidade de projeção de conflitos internos/ externos por meio de atividades artísticas, com a valorização do potencial criativo, imaginativo e expressivo do usuário, além do fortalecimento da autoestima e da autoconfiança, a miscigenação de saberes e a expressão da subjetividade. ${ }^{9}$

As oficinas em Saúde Mental podem ser consideradas terapêuticas quando possibilitarem aos usuários dos serviços um lugar de fala, expressão e acolhimento. Além disso, avançam no caminho da reabilitação, pois exercem o papel de um dispositivo construtor do paradigma psicossocial. ${ }^{10}$

Nesse sentindo, investigações voltadas para os diferentes aspectos dos CAPS potencializam subsídios para a implantação ou consolidação da Reforma Psiquiátrica, ao mesmo tempo em que impulsionam um novo território de pesquisa no âmbito das políticas públicas e da avaliação dos serviços de saúde. ${ }^{11}$

Este estudo representa um recorte de uma pesquisa ${ }^{12}$ mais abrangente e inédita acerca da participação familiar nos CAPS do município de Natal-RN, em meio à organização e implementação dos serviços substitutivos na capital potiguar. Objetivou-se identificar a percepção dos familiares sobre as oficinas terapêuticas desenvolvidas.

\section{MÉTODO}

Pesquisa do tipo exploratória e descritiva, com delineamento qualitativo. 0 estudo exploratório e descritivo tem o objetivo de proporcionar uma visão geral de tipo aproximativo sobre determinado fato, consistindo na análise e descrição de características, ao trabalhar com um universo de significados, motivos, aspirações, valores e atitudes, ou seja, fenômenos que não podem ser quantificados. ${ }^{13}$

0 cenário de desenvolvimento do estudo foram os CAPS II (Oeste e Leste) e CAPSad (Leste e Norte), serviços de saúde mental pertencentes à Secretaria Municipal de Saúde de Natal$\mathrm{RN}$, que oferecem atendimento a portadores de transtornos mentais e àqueles usuários de substâncias psicoativas (álcool e outras drogas).

Foram entrevistados 28 familiares que participavam regularmente dos serviços através de alguma das estratégias de participação oferecidas (Grupo Terapêutico de Familiares, Reunião de Familiares e Assembleia de Usuários, Técnicos e Familiares).

Os familiares assinaram o Termo de Consentimento Livre e Esclarecido (TCLE) em conformidade com os preceitos éticos da pesquisa envolvendo seres humanos, segundo a Resolução 196/96 do Conselho Nacional de Saúde..$^{14}$ A pesquisa foi aprovada pelo Comitê de Ética em Pesquisa da Universidade Federal do Rio Grande do Norte (CEP-UFRN), parecer 118/ 2007. A coleta ocorreu entre os meses de agosto e setembro de 2007, sendo as falas dos familiares gravadas e transcritas na íntegra.
Os depoimentos dos entrevistados são apresentados de maneira semelhante como foram coletados na entrevista semiestruturada, objetivando-se valorizar um modo próprio de ser e de se expressar perante o fenômeno estudado, seguido da identificação do grau de parentesco entre familiar e usuário do serviço, do serviço pesquisado e da entrevista sequencial ( $p$. ex., Esposa, CAPSad Leste, E-7).

\section{RESULTADOS E DISCUSSÃO}

Mediante os achados, foi possível encontrar no discurso dos sujeitos de pesquisa suas percepções acerca das oficinas terapêuticas, de forma geral, relacionadas à importância para o tratamento de seu familiar e funcionamento do CAPS como um todo e à identificação de contradições e falhas na concepção/ desenvolvimento das oficinas.

Dessa forma, destacaram o impacto positivo dos CAPS em suas trajetórias de tratamento e de vida, na melhoria da harmonia familiar, na estabilidade e diminuição das crises do transtorno mental, na redução dos danos associadas ao consumo de drogas, exemplificadas nas falas a seguir:

Pra mim tá bom! 0 atendimento aqui é bom, todo especial. Todos que entram aqui [técnicos] parece quejá foram preparados pra aquilo, atendem muito bem as pessoas (Mãe, CAPSad Norte, E-1).

Sei que os profissionais são da melhor qualidade, só isso que eu tenho a dizer. Não tenho o que me queixar. [...] todos os familiares são pessoas privilegiadas por ter uma assistência dessas (Mãe, CAPS II Leste, E-25).

A satisfação dos familiares entrevistados com o CAPS é tão grande que mesmo quando o pesquisador faz menção às oficinas terapêuticas enquanto foco da entrevista, eles se sentem "obrigados" a falar da felicidade e da satisfação ao terem seus familiares em tratamento nestes serviços substitutivos, conforme as manifestações discursivas:

Eles [técnicos] aqui acolhem eles [usuários], conversam, participam da oficina [...]. É importante que as pessoas por aqui vejam que eles [usuários] são pessoas, é gente, ser humano que precisa ser tratado com amor (Mãe, CAPS II Oeste, E-16).

Peço a Deus que continue esse CAPS para sempre, que tá tirando muita gente aí das drogas, sobre as drogas, o alcoolismo e o estresse, principalmente pra gente que é da família, que a gente vem, tem sempre as nossas reuniões aqui (Irmão, CAPSad Leste, E-20). 
E aqui desde a pessoa da portaria, cozinha, até 0 salão, são pessoas que se doam de uma maneira tal, com paciência, com individualidade (Mãe, CAPS II Leste, E-22).

A propriedade que estes familiares possuem ao falar do funcionamento do CAPS, da equipe técnica e do desenvolvimento das atividades terapêuticas decorre da participação deles no serviço, no maior ou menor grau de engajamento das discussões e decisões tomadas na Assembleia de Usuários, Técnicos e Familiares, e nas Reuniões de Familiares, mesmo considerando que a inclusão/inserção da família ainda seja um desafio nestes serviços e na assistência em saúde mental contemporânea. ${ }^{12}$

Ao falarem mais especificamente sobre as oficinas terapêuticas, os entrevistados ressaltam a possibilidade de crescimento no desempenho dos CAPS, ainda que existam falhas e contradições, denunciam e apontam caminhos em busca da superação das dificuldades:

Aí dentro numa sala [CAPS], tem muita coisa que tá feito ali dentro e vai mofar ali. Tem que fazer alguma coisa, tem que botar pra fora, e mobilizar, quem administre junto com a gente, junto com eles [usuários], por que não é os três, né? (Mãe, CAPS II Oeste, E-16).

0 ideal seria, vamos dizer, funcionar vinte $e$ quarto horas, tivesse um internamento no caso de uma necessidade. Eu acho que isso daí já ajudaria bem mais, porque a gente fica às vezes aqui aflito, né? 0 mais [...] aumentar mais umas 'oficina' (Mãe, CAPS II Leste, E-24).

Estas falas revelam duas situações distintas, com mecanismos, práticas ou ideais circunscritos no bojo das ações em saúde mental a partir da reabilitação psicossocial e das propostas reformistas. A primeira denota claramente a interface entre arteterapia e terapia ocupacional, e a segunda, a ideia de serviço substitutivo com funcionamento 24 horas (CAPS III), ainda inexistente na rede de serviços de saúde mental da capital potiguar.

As oficinas terapêuticas são atividades realizadas em grupo com a presença e orientação de um ou mais profissionais, e constituem uma das principais formas de tratamento oferecido nos CAPS. Essas atividades são programadas mediante 0 interesse dos usuários, as possibilidades dos técnicos ou as necessidades do serviço no projeto terapêutico, objetivando maior integração sociofamiliar. ${ }^{6}$

Podem ser do tipo expressiva (artístico/cultural expressão plástica, corporal, verbal ou musical), alfabetizadora (exercício da escrita e da leitura) ou ainda geradora de renda. Essa última serve como instrumento do aprendizado de uma atividade específica, que pode ser igual ou diferente da profissão do usuário. ${ }^{6}$

Independente da identificação familiar estabelecida, mediante a vivência no serviço e ao longo da vida no acompanhamento do usuário, infere-se que se estes sujeitos, sem considerar a intensidade participativa, possuem a capacidade de identificar nos CAPS falhas, demandas reprimidas, facultadas aos mesmos, e ainda opinar invariavelmente sobre 0 seu funcionamento; isso ocorre porque há participação e abertura para que assim percebam, investiguem, indaguem, ou mesmo se enganem.

Por outro lado, a necessidade sentida, respeitada a proporcionalidade da convivência familiar na redefinição dos limites como uma zona de risco, os faz expectar propostas a partir da crença pessoal sobre como resolver aquilo que considera problemas na esfera familiar e da reabilitação psicossocial.

Tal posicionamento discursivo gera esperanças traduzidas em um fator positivo perante os desafios que os CAPS investigados ainda possuem na busca da melhoria do serviço oferecido, muito embora os familiares ainda não compreendam todos os aspectos estruturais e organizacionais imbricados no funcionamento, incluindo-se os recursos materiais e humanos, conforme o trecho destacado:

E inclusive a abertura que nós familiares temos em relação à equipe técnica de falar, de dizer, de conversar, de superar. Nós temos essa liberdade. Não nos é tolhida, entendeu? [...] Há momentos em que a atividade não deixa de funcionar. Agora, poderia funcionar mais ampliada, mais recursos, mais material didático. Aula de dança, pintura, tudo isso existe, mas poderia ser mais ampliado (Mãe, CAPS II Leste, E-22).

Outro desafio lembrado nas entrevistas pelos familiares foi a necessidade de qualificação profissional dos usuários através da aprendizagem de um ofício, ou seu estágio máximo, o de inserção no mercado de trabalho, correlacionando-os às oportunidades emanadas das oficinas terapêuticas, talvez revelando aí um desconhecimento sobre os objetivos da agenda terapêutica dos CAPS investigados:

Melhorar? Só se tivesse um trabalho pra eles [os usuários] aqui, que eles pudessem fazer, praticando, pra ver se esquecia daquele problema da bebida... Ou mesmo da droga. Se tivesse um trabalho, pra ver se aprendia alguma coisa (Mãe, CAPSad Norte, E1).

Eu pensei também no início que isso daqui [CAPS] preparasse para uma especialidade, para um emprego lá fora, tudo isso eu pensei, mas é pensar demais. Um dos maiores problemas que 


\section{Oficinas terapêuticas como instrumentos para recuperaão Psicossocial}

eu acho pra quem tem transtorno mental é porque não existe um programa nacional, de governo federal, municipal ou estadual. [...] Qualquer deficiência tem uma programação, um emprego, até vaga pra certas empresas. Pra transtorno mental é uma coisa que não existe. Ele [filho] tem capacidade de assumir, é claro, dentro dos limites dele (Mãe, CAPS II Leste, E-24).

Uma oficina de fazer trabalhos manuais pra vender, pra distribuir, pra ajudar [...]. Tá ótimo, tá muito bom, mas eles [usuários] precisam trabalhar! Eu queria que eles trabalhassem, aquilo que você vai fazendo, é como se fosse um exercício mental. Tá bom demais como está, mas se pudesse um trabalho pra vender [...] pra fazer bola, sapato, sapateiro. Eu tô querendo muito! Eu tô querendo demais [...] (Mãe, CAPS II Leste, E-25).

Qual estará sendo o papel dessas atividades nos serviços estudados, tendo em vista os depoimentos de alguns dos familiares? As oficinas existem somente como parte de um cronograma estático, passa-tempo, ou são pensadas, desenvolvidas e planejadas de forma dinâmica, articulada com os demais domínios do conhecimento profissional, segundo as necessidades e as possibilidades dos técnicos, usuários e familiares, na intenção de ser terapêutica? É destacada a inventividade e a produção de existências subjetivas dos usuários?

É certo que esse tipo de atividade é complexa, possui um caráter interdisciplinar, com objetivos comuns entre a equipe, além de envolver demandas diversificadas dos usuários, dos familiares e dos técnicos. A equipe técnica do CAPS opera diferentes instrumentos de trabalho, recursos materiais, conhecimentos especializados multiprofissionais e técnicas (oficinas terapêuticas; atividades de grupo e individuais; consulta médica, psicológica e de enfermagem).

Nesse contexto, pensar no mero envolvimento dos profissionais, na justaposição e divisão de ações técnicas, ${ }^{15}$ na utilização do tempo como "terapêutica paliativa" na execução de atividades descontextualizadas com as necessidades do usuário, transforma-se na mesma ideia de atenção focada na clínica psiquiátrica, da doença mental, em detrimento do desenvolvimento de potencialidades do sujeito psicossocial que se apresenta.

Pode-se falar em oficinas terapêuticas quando essas conseguirem desenvolver outras e melhores conexões que as rotineiramente existentes entre produção desejante e produção da vida material, pois quando se deseja produzir territórios existenciais através da arte ou do trabalho, espera-se que se fale não em adaptação à ordem estabelecida, mas em fazer com que arte e trabalho se engendrem com o princípio livre da criação, com o desejo, ou ainda com o plano de produção da vida. ${ }^{16}$

Entretanto, nem sempre a produção da vida encontra apoio das redes sociais, da indústria, do comércio, ou de outra atividade trabalhista, pois ainda persiste o "medo ou descrédito" perante o louco, e a "periculosidade e criminalidade" dos usuários de substâncias psicoativas.

Dito de outra maneira, resguardadas as devidas proporções, as oficinas terapêuticas não podem ser desenvolvidas mediante cronogramas fechados de trabalho, que se dita o quê, como ou quando fazer, em detrimento da escolha, da invenção, das necessidades dos usuários no contexto de sua subjetividade e de seu sofrimento mental ou uso de drogas.

Portanto, a existência da oficina em si não dá a garantia de que os usuários gozarão da autonomia de seus desejos, anseios e aspirações criadoras, na situação real de vivência do "trabalho-arte-aprendizagem" a ser experimentada, mesmo oportunizando o repensar sobre um agir ajustado às suas incapacidades e potencialidades.

Ainda sobre os achados, nenhum dos familiares mencionou "esse ou aquele" membro da equipe técnica, remetendo duas possibilidades: ou as oficinas existem de maneira integrada com toda a equipe participando, ou elas são tão efêmeras ao ponto de os familiares não perceberem qual ou quais são os profissionais responsáveis.

Em estudo desenvolvido sobre o funcionamento das oficinas terapêuticas em um dos CAPS II aqui pesquisados, os autores concluíram que as oficinas serviam, apenas, como meros dispositivos de ocupação do tempo, mediante a realização de tarefas a ser cumpridas, estando a iniciativa de realização a cargo dos técnicos e não dos usuários. Nesse sentido, a capacidade criativa dos usuários foi negligenciada com oficinas e situações previamente "inventadas". ${ }^{15}$

Prosseguindo, os autores afirmaram que as oficinas ocupavam grande parte do tempo de permanência dos usuários no CAPS, e, inevitavelmente, da equipe técnica, o que culminava na inviabilização de outras estratégias assistenciais voltadas para trabalhos externos e articulados com a comunidade e com outros serviços e instituições. ${ }^{15}$

Um estudo ${ }^{17}$ também identificou pontos geradores de tensão no funcionamento de oficinas terapêuticas de um dos CAPS investigados em seu estudo, nas quais os usuários eram impedidos de escolher em qual atividade gostariam de participar, além da existência de uma escala diária, rígida e fechada, portanto, pré-estabelecida verticalmente, obrigando-os a participar das oficinas. A escala era confeccionada conjuntamente entre a coordenação do CAPS e o psiquiatra, com objetivo claro de controle, normalização da ordem e "produção".

Em virtude de a participação familiar nos CAPS ser um dos critérios de inclusão dos sujeitos nessa pesquisa, o último questionamento da entrevista enfocou esta temática como 
forma de consolidar ainda mais os achados e as percepções advindas das falas anteriores sobre as oficinas terapêuticas.

Dessa forma, os familiares percebem os espaços de participação nos CAPS como formas importantes de acompanhamento do seu familiar usuário, o que gera satisfação e prazer nos encontros, pois além do caráter de orientação nos cuidados fora e dentro do lar, eles também ajudam no crescimento mútuo do grupo:

Como tá a nossa vida, o que tá se passando com a gente, e dentro do grupo a gente vai conversando, uma ajuda à outra e às vezes a gente encontra uma solução pra aquilo. Qualquer coisa que tenha aqui, que seja aberto aos familiares, eu participo (Esposa, CAPSad Leste, E-6).

Atividades é de reunião, é de bom conselho, é de participar da vida dele [irmão], como é que ele vai, do dia-a-dia, entendeu? A gente batendo palestra, conversando sobre lá fora também com o pessoal, tudo isso. Comemoração, aniversário, entrada de ano novo [...] aí vem toda a família [...] é muito importante a família participar, né? Muito importante mesmo (Irmão, CAPSad Leste, E-20).

Apesar dessa satisfação, notou-se durante 0 desenvolvimento das entrevistas que alguns familiares não dão a devida impor tância a essas atividades, pois na maioria das vezes não as identificam como formas de participação.

Nesse sentido, a equipe multiprofissional em saúde mental deve, portanto, reforçar e demonstrar a relevância da presença dos familiares no serviço, informando-os que eles são parceiros e corresponsáveis pelo tratamento do usuário; como tal, é através dessa participação que se pretende atingir a aderência ao tratamento a partir do vínculo e a responsabilidade mútuos requeridos, aproximando-se do ideal de inserção familiar no serviço.

\section{CONCLUSÕES}

As oficinas terapêuticas representam um instrumento importante de ressocialização e inserção individual em grupos, na medida em que propõe o trabalho, o agir e o pensar coletivos, conferidos por uma lógica inerente ao paradigma psicossocial que é respeitar a diversidade, a subjetividade e a capacidade de cada sujeito.

Os familiares entrevistados percebem bem o papel e a importância delas no cenário dos CAPS investigados, apontam falhas e caminhos a serem superados, e ainda despertam o interesse em continuar crescendo no serviço, a despeito da boa evolução e diminuição das crises de seu parente. Dessa forma, a percepção elaborada pelos familiares é de que as oficinas terapêuticas representam instrumentos importantes de (re)socialização e reabilitação psicossocial, admitindo a importância da inovação e diversificação destas atividades no cenário da saúde mental.

A Reforma Psiquiátrica em curso defende a (re)socialização e atendimento ao portador de sofrimento psíquico e seu eixo familiar através de uma série de dispositivos de saúde (CAPS, Ambulatórios de Saúde Mental, Leitos Psiquiátricos em Hospitais Gerais, Urgência e Emergência Psiquiátricas), e iniciativas de desospitalização e renda (Serviços Residenciais Terapêuticos - SRT's, Programa de Volta para Casa, Cooperativas de Trabalho e Lares Abrigados).

Apesar de reconhecidos os avanços desta política, seja no aumento da oferta dos serviços substitutivos, na transferência de gastos realizados no atendimento comunitário, na melhoria da qualidade de vida de vários usuários e familiares ou na desconstrução gradativa do estereótipo da loucura e do uso/abuso de drogas, ainda persistem antigos problemas e o surgimento de novos.

Em algumas regiões do país, o hospital ainda representa a principal ou única oferta de "tratamento" em saúde mental, prevalecendo a lógica mercantilista da loucura e da culpabilização/omissão familiar. A rede extrahospitalar de serviços substitutivos que se organiza admite sérios problemas de entendimento do paradigma psicossocial e desinstitucionalizante, a ponto de desenvolver nos CAPS, SRT's e leitos em hospitais gerais, a mesma lógica punitiva, segregadora e ordenadora do manicômio.

É fato que somente construir uma infraestrutura diferente do manicômio, com todo um arsenal de trabalho em grupo, oficinas terapêuticas diversas, e operar mudanças legais no cenário da psiquiatria/saúde mental não é o bastante. Faz-se necessário investir nos profissionais de saúde que, juntamente com a lógica psiquiatrizante, mudaram para uma nova forma de cuidado e assistência comunitárias, além daqueles profissionais que surgiram e ainda surgem no transcurso da Reforma, mas desconhecem sua existência e não contemplam a discussão em sua formação.

0 movimento de defesa pela Reforma deve ser construído socialmente, a despeito da própria Reforma Sanitária e do SUS, idealizado e construído diariamente. A formação em saúde dirigida para a problemática da assistência em saúde mental e da Reforma, além da investigação bem direcionada através de pesquisas científicas na universidade, representam dois pilares importantes de perpetuação desta discussão no cenário da saúde mental brasileira. 


\section{REFERÊNCIAS}

1.Azevedo DM, Silva DS. The nursing staff and new practices in mental health: the residential therapeutic service as background. Rev Enferm UFPE On line. 2010; [citado 2010 jan 5]; 4(1):450-53. Disponível em: http://www.ufpe.br/revistaenfermagem/index.php/revista/article/view/718/ 493

2.Azevedo DM, Miranda FAN. Práticas profissionais e tratamento ofertado nos CAPSad do município de Natal-RN: com a palavra a família. Esc Anna Nery. 2010 jan/mar; 14(1): 56-63.

3.Azevedo DM, Miranda FAN. The family and substitute services in mental health: a clipping of the brazilian literature in nursing. Rev Enferm UFPE On line. 2009; [citado 2009 maio 04]; 3(1): 93-98. Disponível em: http:// unw.ufpe.br/revistaenfermagem/index.php/enfermagem/article/view/257/ 295

4.Bielemann VLM et. al. A inserção da família nos centros de atenção psicossocial sob a ótica de seus atores sociais. Texto\&Contexto Enferm. 2009 jan/mar; 18(1): 131-39.

5.Delfini PSS, Sato MK, Antoneli PP, Guimaraes POS. Parceria entre CAPS e PSF: o desafio da construção de um novo saber. Cienc Saude Colet. 2009; 14(supl. 1): 1483-92.

6.Ministério da Saúde (BR). Saúde mental no SUS: os centros de atenção psicossocial. Brasília (DF); 2004.

7.Ministério da Saúde (BR). Relatório de Gestão: 2003-2006. Saúde mental no SUS: acesso ao tratamento e mudança do modelo de atenção. Brasília (DF); 2007.

8.Tavares CMM. 0 papel da arte nos centros de atenção psicossocial CAPS. Rev Bras Enferm. 2003; 56(1): 35-9.

9.Martins AKL, Oliveira JD, Silva KVLG, Moreira DA, Souza AMA. Therapeutic workshops in the perspective from CAPS' users: a descriptive study. Rev Enferm UFPE On line. 2010; [citado 2010 jan 15]; 4(1):70-6. Disponível em: http://www.ufpe.br/revistaenfermagem/index.php/revista/article/view/ $515 / 443$

10.Lappann-Botti NC, Labate RC. Oficinas em saúde mental: a representação dos usuários dos serviços de saúde mental. Texto\& Contexto Enferm. 2004 out/dez; 13(4): 519-26.

11.0nocko-Campos RT, Furtado JP. Entre a saúde coletiva e a saúde mental: um instrumental metodológico para avaliação da rede de centros de atenção psicossocial (CAPS) do sistema único de saúde. Cad Saude Publica. 2006; 22(5):1053-62.

12.Azevedo DM. Estudo representacional da participação familiar nas atividades dos centros de atenção psicossocial no município de Natal-RN [dissertação]. Natal: Departamento de Enfermagem, Universidade Federal de Natal; 2008.

13.Minayo MCS. Pesquisa social: teoria, método e criatividade. $20^{\mathrm{a}}$ ed. Petrópolis(RJ): Vozes; 2002.
14.Ministério da Saúde (BR). Conselho Nacional de Saúde. Resolução 196, de 10 de outubro de 1996. Diretrizes e normas regulamentadoras de pesquisas envolvendo seres humanos. Brasília(DF); 1996.

15.Cedraz A, Dimenstein M. Oficinas terapêuticas no cenário da reforma psiquiátrica: modalidades desinstitucionalizante ou não? Rev Mal-estar Subjet. 2005 set; 5(2): 300-27.

16. Rauter C. Oficinas para quê? uma proposta ético-estético-política para as oficinas terapêuticas. In: Amarante P, organizador. Ensaios, subjetividade, saúde mental, sociedade. $2^{\mathrm{a}}$ ed. Rio de Janeiro: Fiocruz; 2006. p. 267-77.

17.0liveira JAM. 0 processo de desinstitucionalização da loucura em serviços de saúde mental no estado de Sergipe: um problema clínicopolítico [dissertação]. Rio de Janeiro: Programa de Pós-Graduação em Psicologia Social, Universidade Federal Fluminense; 2006. 